\title{
SOME CHARACTERISTICS OF THE RESULTANT AIR FLOW FROM MOTIONS INDUCED BY VENTILATION AND HEAT SOURCE IN A TWO-DIMENSIONAL ENCLOSURE
}

\author{
T. V. Tran*, N. T. Thuy \\ VNU, University of Science, Hanoi, Vietnam \\ *E-mail: trantv@vnu.edu.vn \\ Received January 19, 2014
}

\begin{abstract}
Ventilated air flow in an enclosure is often unsteady (turbulent) at even very low Reynolds number $(R e)$. Meantime natural convection in a box is stationary motion at large enough Rayleigh number $(R a)$. This paper deals with the interaction between two those flows in a two-dimensional room. The room has one inlet and one or two outlets. A heat source locates on the floor. The numerical simulation of the interaction is carried out at some values of Re and Ra for two cases of the inlet and outlet configuration. Some interesting characteristics of the resultant flow are discovered. The heat amount released by the source and removed from the room by different types of this flow is also provided.
\end{abstract}

Keywords: Ventilation, convection, interaction, heat source, inlet, outlet.

\section{INTRODUCTION}

Ventilation of living or working enclosed spaces has permanent practical interest. Removal of heat from a large industrial factory or small electronic equipment by ventilation has been a challenging problem for both theoretical investigation and practical application. An overview on studies related to this subject is done in the work of Qingyan Chen [1].

Natural convection in various enclosed spaces caused by heating or cooling boundary or inside heat sources has been investigated intensively since publishing Chandrasekhar's book [2]. Many of these studies concern the instability of such convective motion. Later researchers have paid more attention to applied aspect of the problem by considering natural or mixed convection in living or working enclosed spaces [3-6]. The main concern of such investigations is to calculate the velocity field evoked by the convection as well as the temperature distribution in the enclosure. In paper [7] a warm air is supplied to a two-dimension room at moderate rates to find the better inlet-outlet location in order to create a good temperature distribution for living condition. Meantime the 
purpose of study [8] is define the efficiency of contaminant removal from an enclosure by clean air flow.

The target of this paper is studying the interaction between ventilation and convection to define what kind of the resultant flow (steady, periodic and quasi-periodic) will occur in dependence on the relationship between the air supply rate $(R e)$ and the intensity of the heat source $(R a)$ for two concrete enclosures.

\section{PROBLEM FORMULATION}

Consider a two-dimensional room $6 \mathrm{~m}$ long and $3 \mathrm{~m}$ height. There are two cases of the inlet-outlet configuration as indicated in Fig. 1.
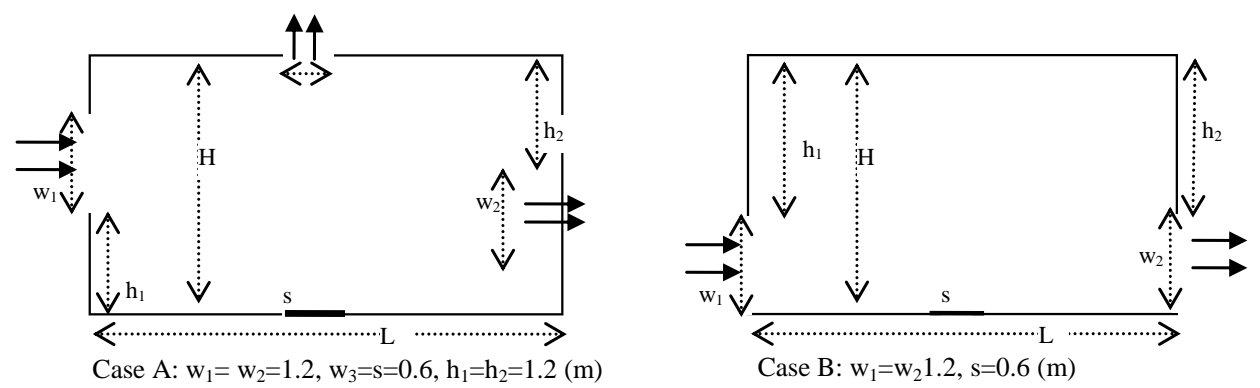

Fig. 1. The geometrical configuration of the room inlet and outlet

In both cases a linear homogeneous isotemperature heat source (s) of length $0.6 \mathrm{~m}$ locates at the middle of the floor. Taking the inlet velocity $U$, the room height $H$, the ratio $H / U$ and the difference between the temperature of the heat source and that at the inlet $\Delta T$ as characteristic values for velocity, length, time and temperature respectively one can obtain the following governing equations for laminar Navier-Stokes system under Boussinesq approximation with constant physical properties

$$
\begin{aligned}
& \frac{\partial u}{\partial x}+\frac{\partial v}{\partial y}=0 \\
& \frac{\partial u}{\partial t}+u \frac{\partial u}{\partial x}+v \frac{\partial u}{\partial y}=-\frac{\partial p}{\partial x}+\frac{1}{R e}\left(\frac{\partial^{2} u}{\partial x^{2}}+\frac{\partial^{2} u}{\partial y^{2}}\right), \\
& \frac{\partial v}{\partial t}+u \frac{\partial v}{\partial x}+v \frac{\partial v}{\partial y}=-\frac{\partial p}{\partial y}+\frac{1}{R e}\left(\frac{\partial^{2} v}{\partial x^{2}}+\frac{\partial^{2} v}{\partial y^{2}}\right)+\frac{R a}{\operatorname{Pr} \cdot R e^{2}} T, \\
& \frac{\partial T}{\partial t}+u \frac{\partial T}{\partial x}+v \frac{\partial T}{\partial y}=\frac{1}{R e \operatorname{Pr}}\left(\frac{\partial^{2} T}{\partial x^{2}}+\frac{\partial^{2} T}{\partial y^{2}}\right),
\end{aligned}
$$

where $u, v, p$ and $T$ are non-dimensional components of velocity, pressure and temperature respectively. The dimensionless values in Eqs. (2), (3) and (4) are the Reynolds number, the Rayleigh number, the Grashof number and the Prandtl number respectively.

$$
\operatorname{Re}=\frac{U H}{v}, R a=\mathrm{Gr} / \mathrm{Pr}, \mathrm{Gr}=\frac{g \beta \Delta T H^{3}}{v^{2}}, \operatorname{Pr}=\frac{v}{\chi},
$$


where $\beta, v, \chi$ are the coefficient of thermal expansion, the kinematic viscosity and the thermal diffusivity of liquid respectively. The boundary condition are set as follows

On the walls: $u=v=T=0$

At the inlet: $u=1, v=T=0$

At the right outlet: $v=0, u=w_{\text {in }} /\left(w_{\text {out } 1}+w_{\text {out } 2}\right)$

At the ceiling outlet: $u=0, v=w_{\text {in }} /\left(w_{\text {out } 1}+w_{\text {out } 2}\right)$

At the heat source: $u=v=0, T=1$

where $w_{\text {in }}, w_{\text {out } 1}, w_{\text {out } 2}$ are the width of the inlet, the right outlet and ceiling outlet respectively.

Following [9] the condition for temperature at the outlets is taken as follows

$$
T_{i}^{n}=\bar{T}_{i}^{n-1}
$$

where $T_{i}^{n}$ is the temperature at the $n$-th time step of integration, $i=1,2$ in the accordance with the right and ceiling outlet, $\bar{T}_{i}^{n-1}$ is the average temperature at the $i$-th outlet and at the previous time step. Note that condition (11) as indicated in [9] is more adequate than the zero flux of heat that usually is set by other researchers. Condition (11) also helps to calculate the removal heat through the every outlet at any time step.

\section{NUMERICAL METHOD}

In this paper the solution of governing equations (1)-(4) with boundary condition (6)-(11) and the initial condition

$$
u=v=T=\left.C\right|_{t=0}=0,
$$

is calculated by FEM. The crucial idea of the FEM procedure applied in this study is CBS (Characteristic Based Split) scheme first proposed by Zienkiewics and Cordina [10] and further developed by Zienkiewicz et al. [11] and by Nithiarasu [12]. This procedure is presented in a very good detail in [13]. The CBS scheme includes four steps at every time step of integration of the problem. These steps are the following:

Step 1: Calculating the intermediate velocity $u^{*}, v^{*}$

$$
\begin{aligned}
\frac{u^{*}-u^{n-1}}{\Delta t}= & -u \frac{\partial u^{n-1}}{\partial x}-v \frac{\partial u^{n-1}}{\partial y}+\frac{1}{R e}\left(\frac{\partial^{2} u}{\partial x^{2}}+\frac{\partial^{2} u}{\partial y^{2}}\right)^{n-1}+ \\
& +\frac{u \Delta t}{2} \frac{\partial}{\partial x}\left(u \frac{\partial u}{\partial x}+v \frac{\partial u}{\partial y}\right)^{n-1}+\frac{v \Delta t}{2} \frac{\partial}{\partial y}\left(u \frac{\partial u}{\partial x}+v \frac{\partial u}{\partial y}\right)^{n-1} \\
\frac{v^{*}-v^{n-1}}{\Delta t}=- & u \frac{\partial v^{n-1}}{\partial x}-v \frac{\partial v^{n-1}}{\partial y}+\frac{1}{R e}\left(\frac{\partial^{2} v}{\partial x^{2}}+\frac{\partial^{2} v}{\partial y^{2}}\right)^{n-1}+\frac{u \Delta t}{2} \frac{\partial}{\partial x}\left(u \frac{\partial v}{\partial x}+v \frac{\partial v}{\partial y}\right)^{n-1}+ \\
& +\frac{v \Delta t}{2} \frac{\partial}{\partial y}\left(u \frac{\partial v}{\partial x}+v \frac{\partial v}{\partial y}\right)^{n-1}+\frac{R a}{\operatorname{Pr}^{*} R e^{2}} T^{n-1}
\end{aligned}
$$


Step 2: Calculating pressure

$$
\frac{1}{\rho}\left(\frac{\partial^{2} p}{\partial x^{2}}+\frac{\partial^{2} p}{\partial y^{2}}\right)^{n-1}=\frac{1}{\Delta t}\left(\frac{\partial u}{\partial x}+\frac{\partial v}{\partial y}\right) .
$$

Step 3: Correcting the velocity

$$
\begin{aligned}
& \frac{u^{n}-u^{*}}{\Delta t}=-\frac{1}{\rho} \frac{\partial p^{n-1}}{\partial x}+\frac{u \Delta t}{2} \frac{\partial}{\partial x}\left(\frac{1}{\rho} \frac{\partial p}{\partial x}\right)^{n-1}+\frac{v \Delta t}{2} \frac{\partial}{\partial y}\left(\frac{1}{\rho} \frac{\partial p}{\partial x}\right)^{n-1}, \\
& \frac{v^{n}-v^{*}}{\Delta t}=-\frac{1}{\rho} \frac{\partial p^{n-1}}{\partial y}+\frac{u \Delta t}{2} \frac{\partial}{\partial x}\left(\frac{1}{\rho} \frac{\partial p}{\partial y}\right)^{n-1}+\frac{v \Delta t}{2} \frac{\partial}{\partial y}\left(\frac{1}{\rho} \frac{\partial p}{\partial y}\right)^{n-1} .
\end{aligned}
$$

Step 4: Calculating temperature

$$
\begin{aligned}
\frac{T^{n}-T^{n-1}}{\Delta t}= & -u \frac{\partial T^{n-1}}{\partial x}-v \frac{\partial T^{n-1}}{\partial y}+\frac{1}{\operatorname{Pr} \cdot \operatorname{Re}}\left(\frac{\partial^{2} T}{\partial x^{2}}+\frac{\partial^{2} T}{\partial y^{2}}\right)^{n-1}+ \\
& +\frac{u \Delta t}{2} \frac{\partial}{\partial x}\left(u \frac{\partial T}{\partial x}+v \frac{\partial T}{\partial y}\right)^{n-1}+\frac{v \Delta t}{2} \frac{\partial}{\partial y}\left(u \frac{\partial T}{\partial x}+v \frac{\partial T}{\partial y}\right)^{n-1}
\end{aligned}
$$

To increase the accuracy and decrease the computational time a mesh with finer resolution in the vicinity of the inlet, outlets and the heat source is used.

\section{RESULTS AND DISCUSSION}

For recording the change of flow parameters such as $u, v, T$ seven points are chosen in the computational domain. They are numbered as follows: P1 $(1.5,0.5)$, P2 $(1.5,0.3)$, P3(1.5, 0.8), P4 (1,0.8), P5(0.5, 0.8), P6(1, 0.3) and P7 $(0.5,0.3)$.
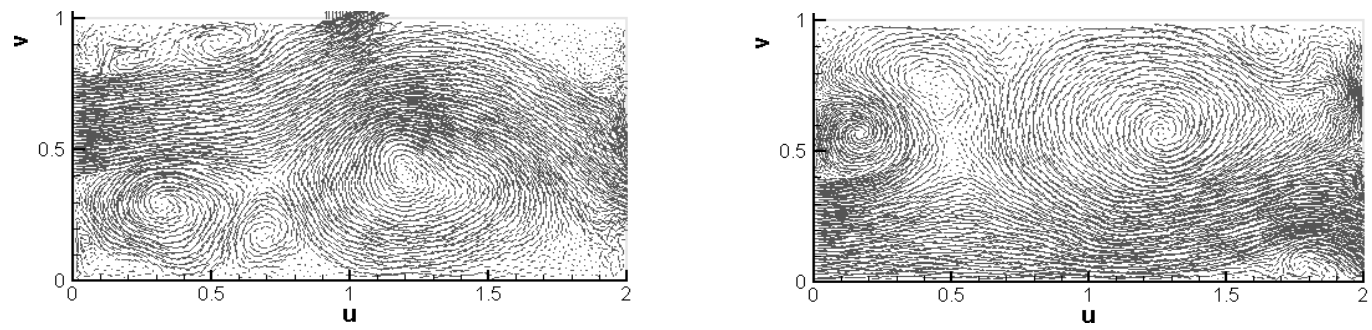

Fig. 2. Velocity field at $R e=20$

So point P1 is the center of the room. Now firstly consider the ventilation flow without any heat source in the enclosure. Fig. 2 shows the velocity fields for case A and $\mathrm{B}$ at $R e=20$. Obviously, even at low Reynolds number the flow in both cases is not smooth. There are several vortices in each case. These vortices make the flow unsteady as shown in Fig. 3 where $u$-component (Fig. 3a) and v-component of velocity (Fig. 3b) at point $\mathrm{P} 1$ are presented. The dot lines represent B-case results.

The velocity at all six remain points has the oscillating character similar to that in Fig. 3. It seems that for the room chosen here a steady ventilated flow without buoyancy can not exist at any rate of the air supply. 


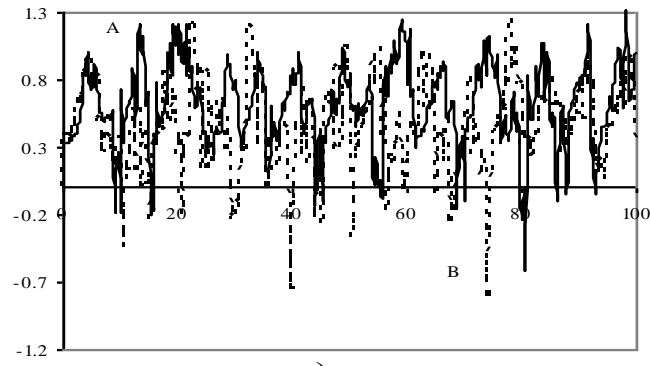

a)

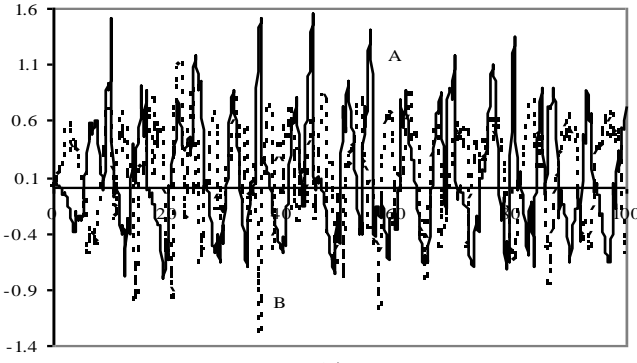

b)

Fig. 3. The change of velocity at $\mathrm{P} 1, \mathrm{Re}=20$

Now let consider the convection caused by only heat source $(s)$ on the floor as indicated in Fig. 1. In this case the room is an enclosure without any inlet and outlet. Fig. 4 shows the air velocity (a: $u$-component, b: $v$-component) at the seven chosen points for $R a=10^{6}$. It is obvious that the convection becomes steady after a short time interval after its onset. The properties of the convective motion at $R a=10^{7}$ is fully different than those at $R a=10^{6}$. As shown in Fig. 5, the natural convection for $R a=10^{7}$ is actually unsteady motion.

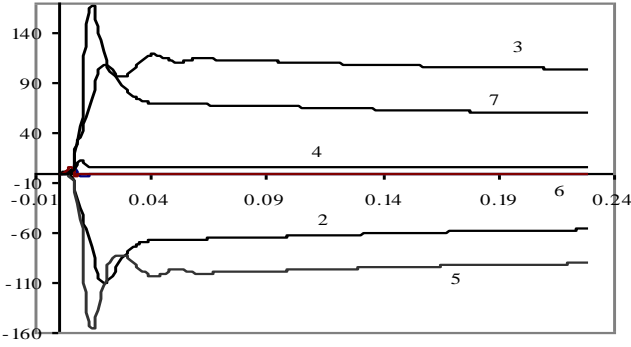

a)

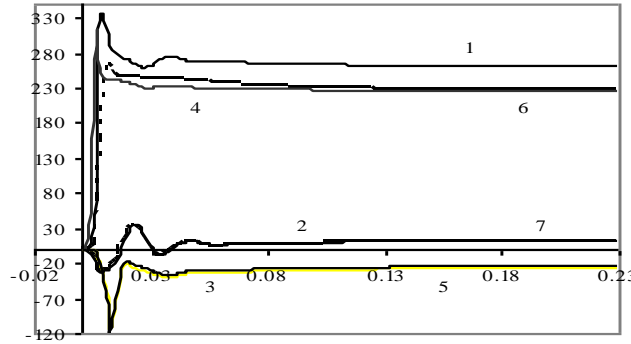

b)

Fig. 4. Velocity at the seven chosen points for $R a=10^{6}$
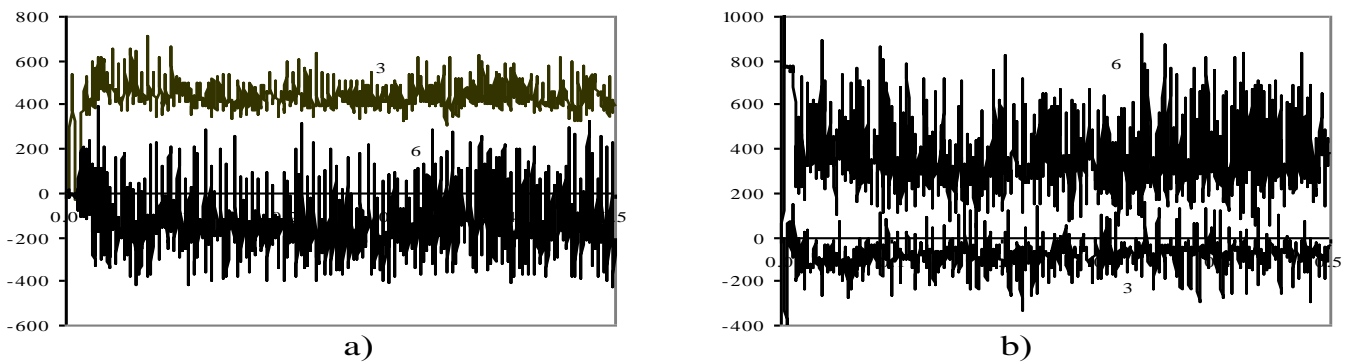

Fig. 5. Velocity at point $\mathrm{P} 3$ and $\mathrm{P} 6$ for $\mathrm{R} a=10^{7}$ (a: $u$-component, $\mathrm{b}: v$-component) 
The difference between the steady convective motion at $R a=10^{6}$ and unsteady convection at $R a=10^{7}$ is more obvious in Fig. 6 where the temperature at point P1 (a) and at point P7 (b) is given for three values of $R a$. This difference is also reflected clearly in Fig. 7 where the velocity field and the temperature distribution are presented for $R a=10^{6}$ and $R a=10^{7}$. Both the velocity and temperature fields are symmetrical at $R a=10^{6}$ meantime this character is not in the presence at $R a=10^{7}$.
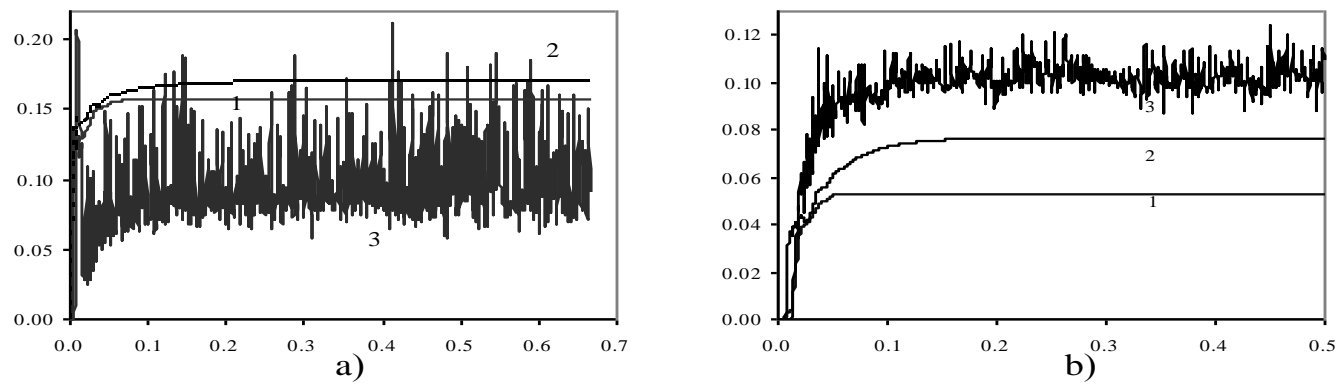

Fig. 6. Temperature at P1 (a), at P7 (b) (1: $\left.R a=10^{5}, 2: R a=10^{6}, 3: R a=10^{7}\right)$
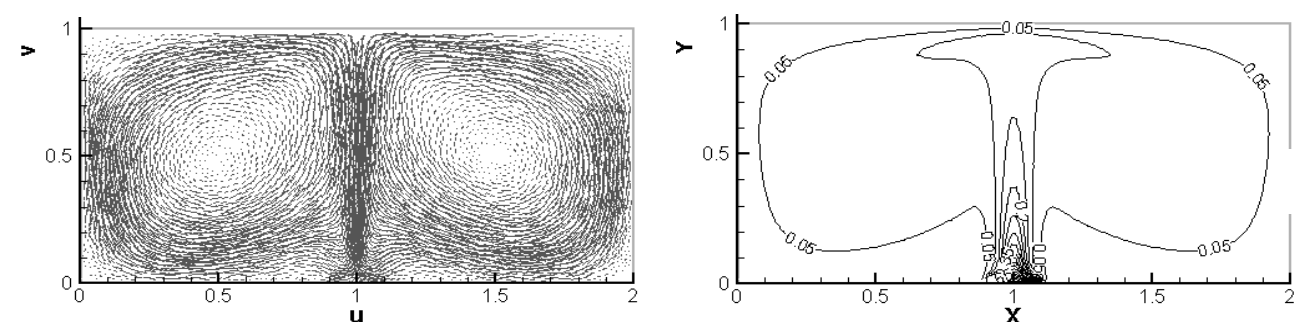

a)
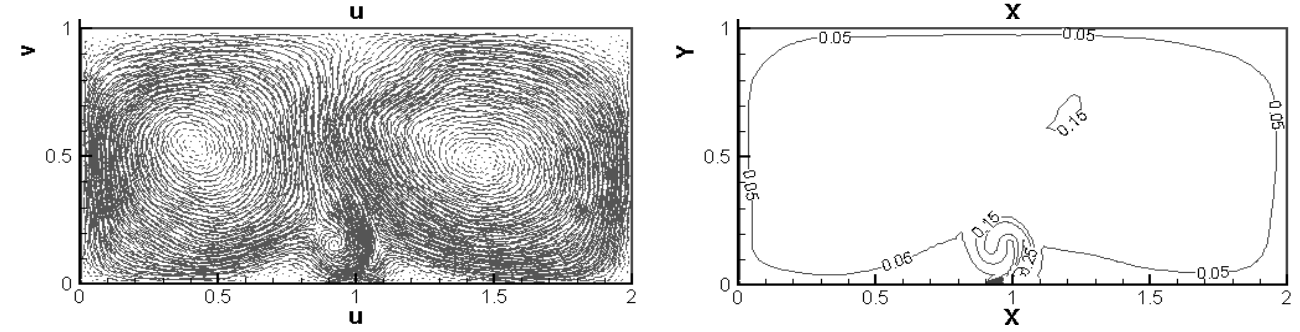

b)

Fig. 7. Velocity field and temperature isolines: a) $R a=10^{6}$, b) $R a=10^{7}$

Now consider the air resultant motion induced simultaneously by ventilation and natural convection in the enclosure shown in Fig. 1. As indicated above, the natural convection is steady at large enough $R a$ meantime the ventilated flow may be unsteady at any $R e$. So it is interesting to study the existence of the stationary resultant flow in the dependence on the relation between Reynolds number and Rayleigh one. The simulation shows that (see Fig. 8) for the both cases $\mathrm{A}$ and $\mathrm{B}$, at $R e=10^{3}$ and $R a=10^{5}$ the resultant air flow is strictly steady, meantime at $R e=10^{3}$ and $R a=10^{7}$ the stationary flow is 


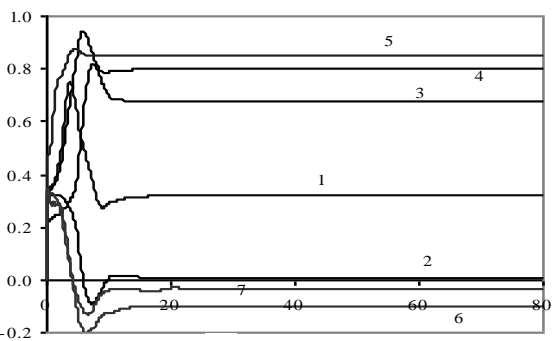

a)

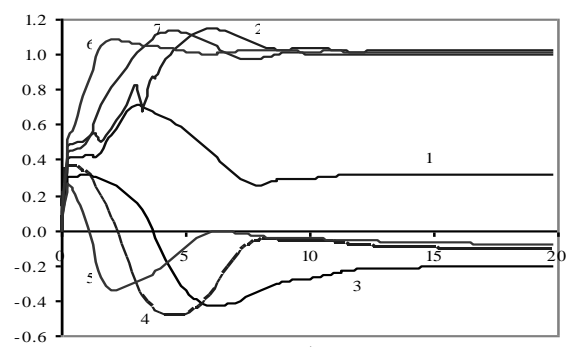

c)

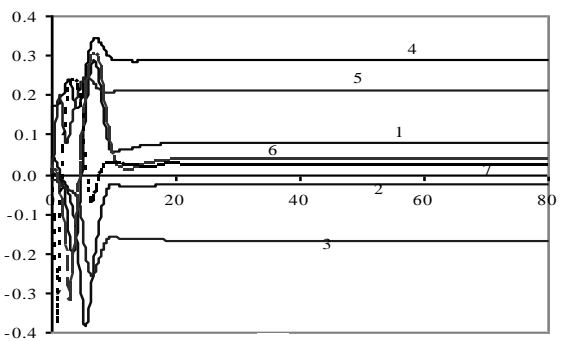

b)

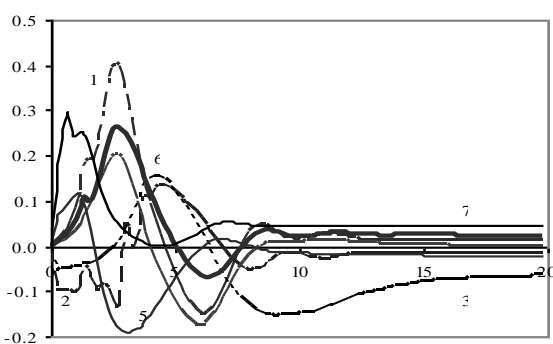

d)

Fig. 8. a) $u$-component, b) $v$-component at seven points for case $\mathrm{A}$ at $R e=10^{3}, R a=10^{5}$ c) $u$-component, d) $v$-component at seven points for case $\mathrm{B}$ at $R e=10^{3}, R a=10^{7}$

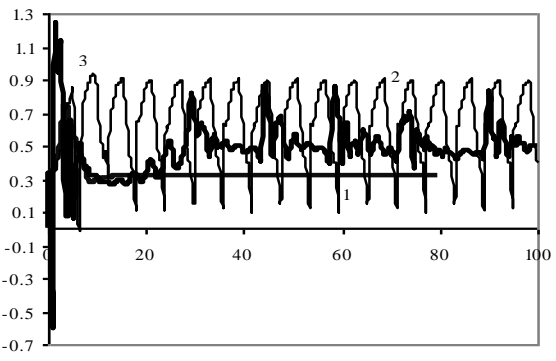

a)
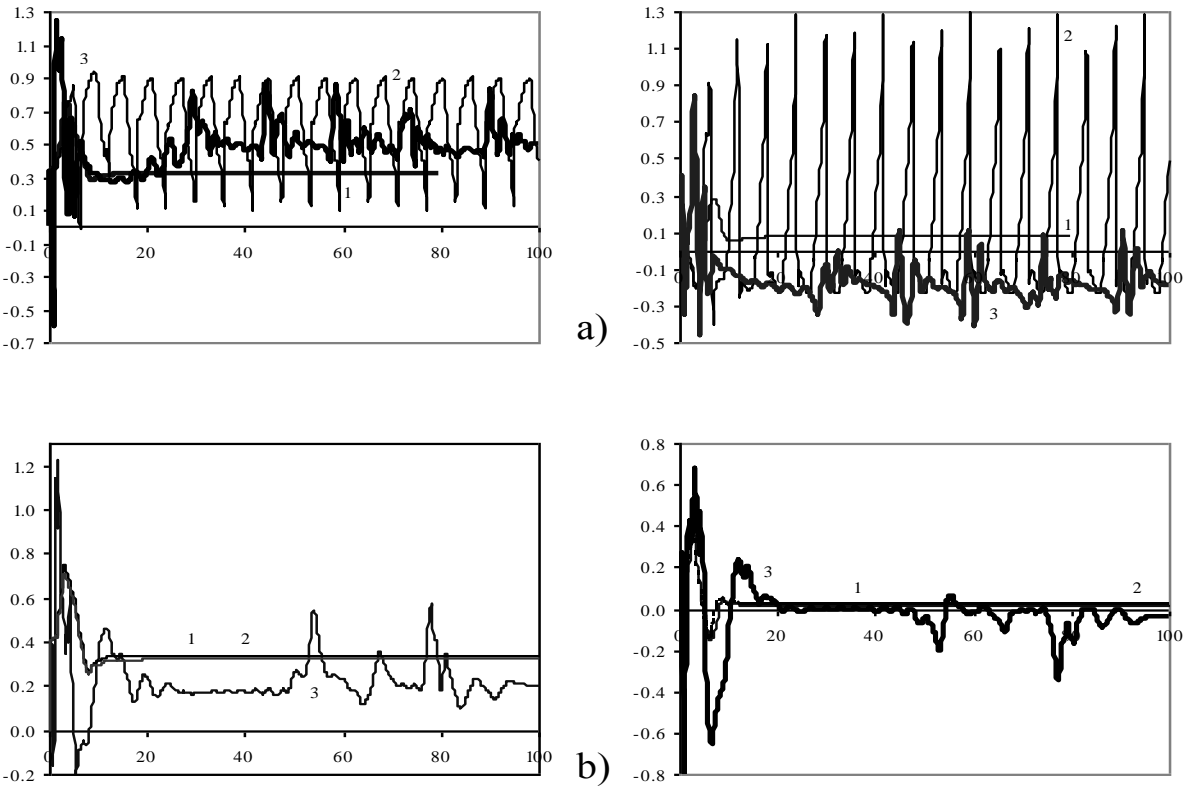

Fig. 9. a) $u$-component and $v$-component at $\mathrm{P} 1$ for case $\mathrm{A}$ at $R e=10^{3}, R a=10^{5}(1), R a=10^{7}(2)$, $\left.R a=10^{8}(3) ; b\right)$ the same for case $\mathrm{B}$ at $R e=10^{3}, R a=10^{5}(1), R a=10^{7}(2), R a=10^{8}(3)$ 
discovered only for case B. Fig. 9 shows the change of the velocity at point P1 for several values of $R a$ at $R e=10^{3}$. It is seen from Fig. 9 that in case $\mathrm{B}$ the air flow is steady for $R a=10^{5}$ and $R a=10^{7}$ and unsteady for $R a=10^{8}$. But in case A the flow is stationary only for $R a=10^{5}$. All the unsteady solutions presented in Fig. 9 seem to be quasiperiodic. It is very interesting to note that the solution corresponding to $R e=10^{3}$ and $R a=10^{7}$ for case $\mathrm{A}$ is exactly periodic.

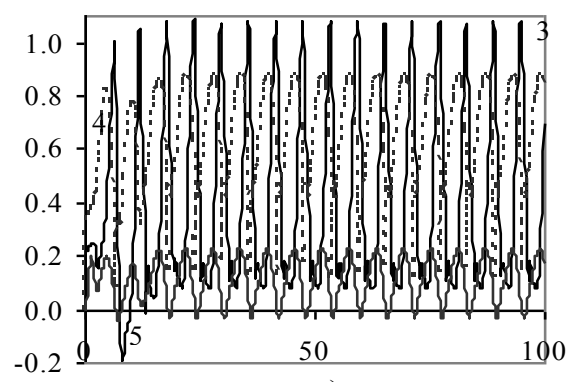

a)

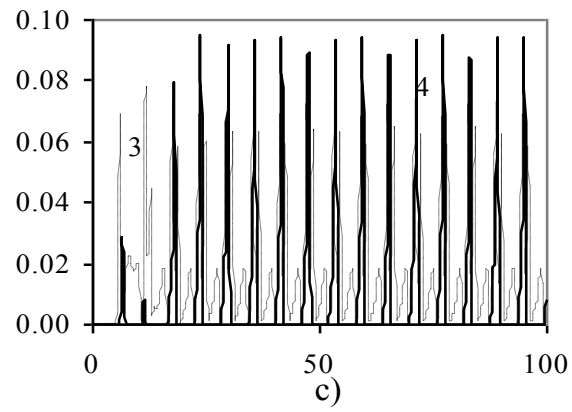

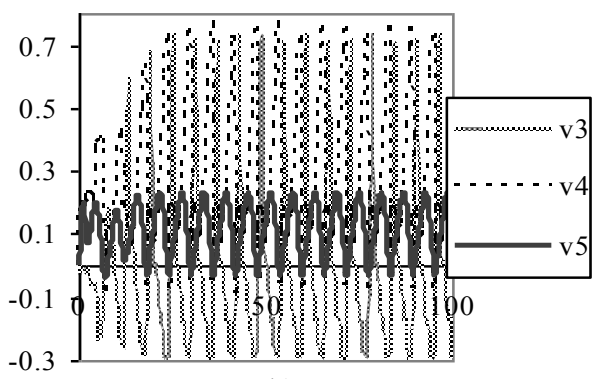

b)

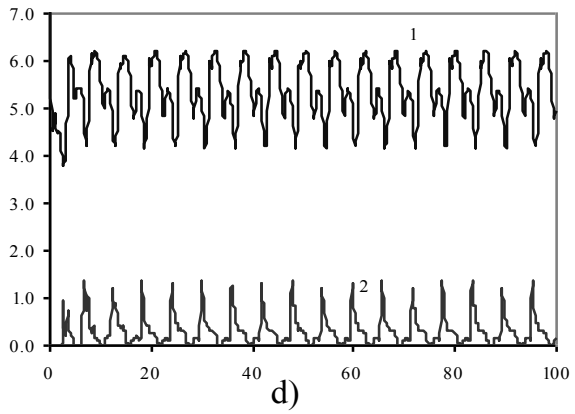

Fig. 10. $u$-component (a) and v-component (b) in P3, P4, P5 for case A at $R e=10^{3}, R a=10^{7}$, (c): temperature in $\mathrm{P} 3, \mathrm{P} 4,(\mathrm{~d})$ : heat flux in (1) and heat flux out (2) for case A at

$$
R e=10^{3}, R a=10^{7}
$$

This solution is presented in Fig. 10. The variation in time of the velocity (a: $u$ component, b: v-component) and the temperature (c) at points P3, P4, P5 as well as the change of the heat flux from the source and the heat flux removed through the inlets (d) in Fig. 10 strongly indicate the periodic character of the solution that presents the air flow for case $\mathrm{A}$ at $R e=10^{3}$ and $R a=10^{7}$. Note that in Fig. 10c, the temperature at point P5 is almost equal to zero at all the time so it is not shown there.

Simulations also show that when Reynolds number Re exceeds $10^{3}$ the resultant flow becomes unsteady at all values of $R a$.

The 'efficiency' of the removal heat from the room in term of the ratio of the instant heat flux out through the outlets over heat flux in released by the source is shown in Fig. 11 for case A and in Fig. 12 for case B. The general conclusion drawn from Fig. 11 and Fig. 12 is that the relative 'efficiency' decreases when Reynolds number based on the air supply increases. This does not mean that the heat flux in and therefore the heat flux out 


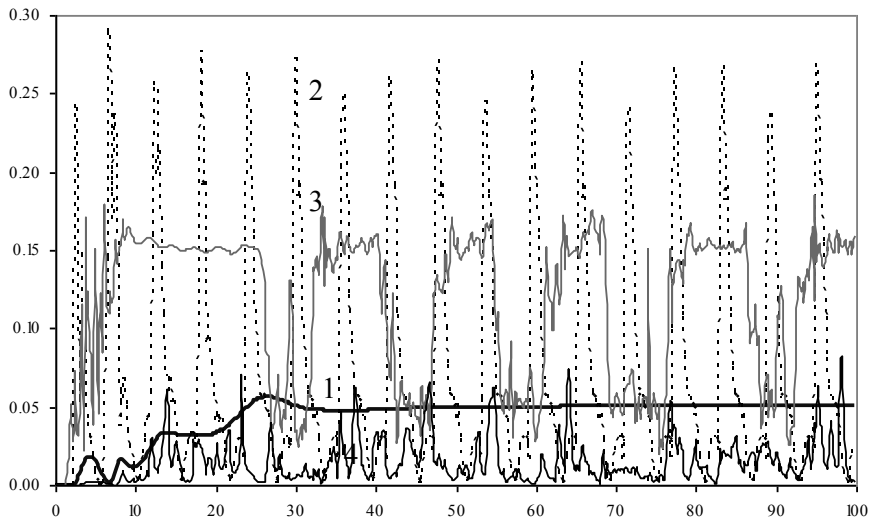

Fig. 11. The ratio (heat flux in)/(heat flux out) for case $\mathrm{A} ; 1-\operatorname{Re}=10^{3}, R a=10^{5}$, 2-Re $=10^{3}, R a=10^{7}, 3-R e=10^{3}, R a=10^{8}, 4-R e=10^{4}, R a=10^{5}$
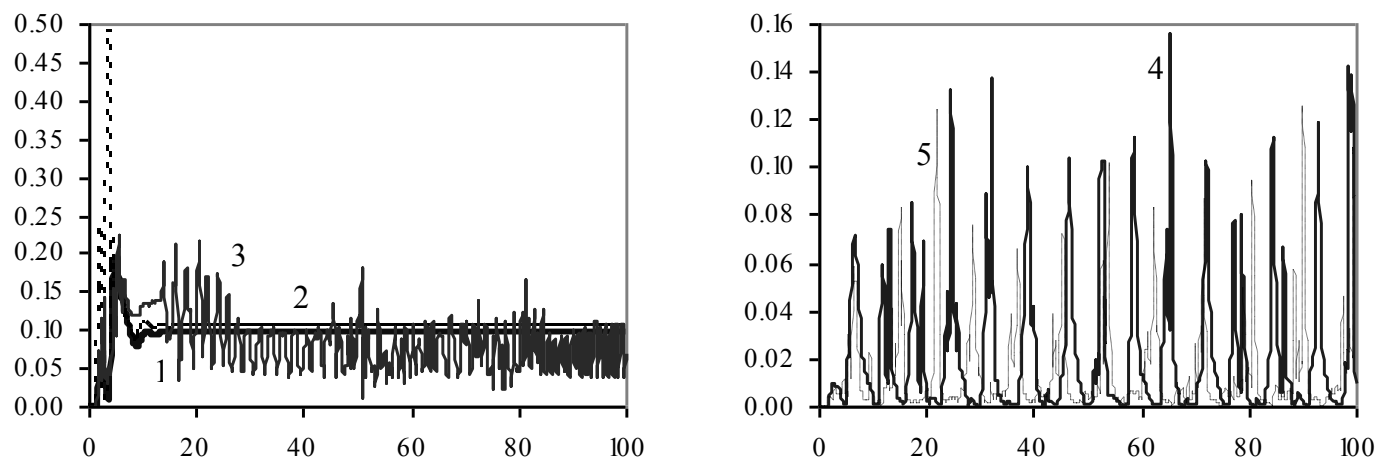

Fig. 12. The ratio (heat flux in)/(heat flux out) for case $B ; 1-R e=10^{3}, R a=10^{5}$, 2-Re $=10^{3}, R a=10^{7}, 3-R e=10^{3}, R a=10^{8}, 4-R e=10^{4}, R a=10^{5}, 5-R e=10^{5}, R a=10^{5}$

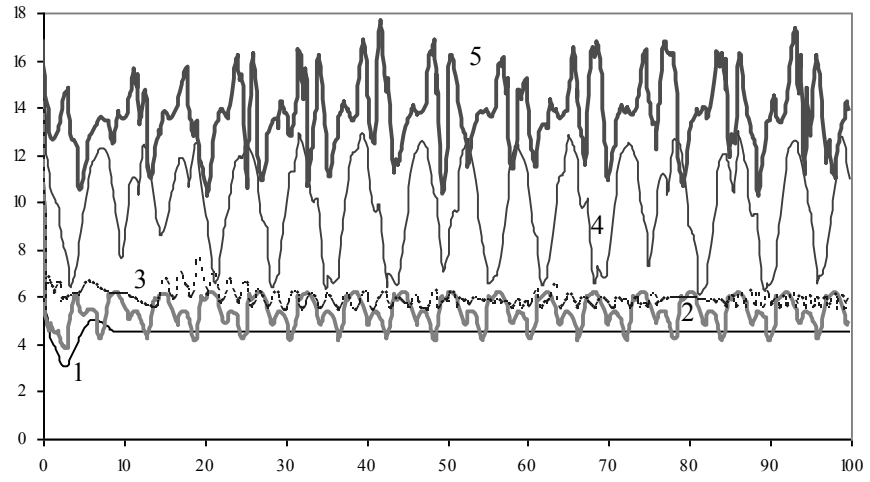

Fig. 13. Instant heat flux released by the source for case $B ; 1-R e=10^{3}, R a=10^{5}$, $2-R e=10^{3}, R a=10^{7}, 3-R e=10^{3}, R a=10^{8}, 4-R e=10^{4}, R a=10^{5}, 5-R e=10^{5}, R a=10^{5}$ 
is in inverse ratio to $R e$. On the contrary, the heat flux and $R e$ are directly proportional quantities. Fig. 13 indicates that at the same $R e$, the more $R a$ the larger the heat flux becomes. Also, for a fixed $R a$ the heat flux increases with Reynolds number.

\section{CONCLUSION}

In the framework of the Navier-Stokes equations with buoyancy in Boussinesq approximation, in this work it is numerically shown that the air flow simultaneously caused by ventilation and natural convection in an enclosure may be steady, periodic or quasi-periodic. This depends on the relationship between the Reynlods number and the Rayleigh number as well as the location of the inlet and outlet of the enclosure. At a moderate $R e$ there exists a limit of $R a$ under which the air flow has to be steady. When Ra exceeds this limit, the motion becomes periodic or quasi-periodic. At large $R e$, the flow as expected is fully unstationary or turbulent at any value of $R a$. This two-dimensional model may be regarded as a good approximation for the case of a long working space any cross section of which is similar to the enclosure considered here.

\section{REFERENCES}

[1] Q. Chen. Ventilation performance prediction for buildings: A method overview and recent applications. Building and Environment, 44, (4), (2009), pp. 848-858.

[2] S. Chandrasekhar. Hydrodynamic and hydromagnetic stability. Clarendon Press Oxford, (1961).

[3] S. Ostrach. Natural convection in enclosures. Advances in Heat Transfer, 8, (1972), pp. 161-227.

[4] T. Terai. Indoor thermal convection. Architectural Institution of Japan, 63, (1959). (in Japanese).

[5] R. Kulkarmi. Natural convection in enclosures with localized heating and cooling. PhD thesis, University Wollongong, Australia, (1998).

[6] G. Saha, S. Saha, M. Q. Islam, and M. R. Akhanda. Natural convection in enclosure with discrete isothermal heating from below. Journal of Naval Architecture and Marine Engineering, 4, (1), (2007), pp. 1-13.

[7] S. L. Sinha, R. C. Arora, and S. Roy. Numerical simulation of two-dimensional room air flow with and without buoyancy. Energy and Buildings, 32, (1), (2000), pp. 121-129.

[8] J. L. Lage, A. Bejan, and R. Anderson. Efficiency of transient contaminant removal from a slot ventilated enclosure. International Journal of Heat and Mass Transfer, 34, (10), (1991), pp. 26032615.

[9] T. V. Tran and N. T. Thuy. The effect of boundary conditions on the efficiency of heat or contaminant removal from a ventilated room. Vietnam Journal of Mechanics, 37, (2), (2015), pp. 133-144.

[10] O. C. Zienkiewicz and R. Codina. A general algorithm for compressible and incompressible flow - Part I. The split, characteristic-based scheme. International Journal for Numerical Methods in Fluids, 20, (8-9), (1995), pp. 869-885.

[11] O. C. Zienkiewicz, P. Nithiarasu, R. Codina, M. Vazquez, and P. Ortiz. The characteristicbased-split procedure: an efficient and accurate algorithm for fluid problems. International Journal for Numerical Methods in Fluids, 31, (1), (1999), pp. 359-392.

[12] P. Nithiarasu. An efficient artificial compressibility (AC) scheme based on the characteristic based split (CBS) method for incompressible flows. International Journal for Numerical Methods in Engineering, 56, (13), (2003), pp. 1815-1845.

[13] W. L. Roland, P. Nithiarasu, and K. N. Seetharamu. Fundamentals of the finite element method for heat and fluid flow. John Wiley \& Sons Ltd, (2004). 